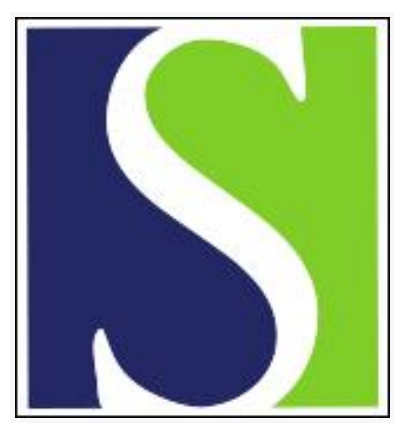

Scand J Work Environ Health 1986;12(6):630-631

https://doi.org/10.5271/sjweh.2091

Issue date: Dec 1986

Testicular cancer among agricultural workers and licensed pesticide applicators in Sweden.

by Wiklund K, Dich J, Holm LE

This article in PubMed: www.ncbi.nlm.nih.gov/pubmed/3823814

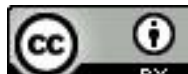


Scand J Work Environ Health 12 (1986) 630-631

\section{Testicular cancer among agricultural workers and licensed pesticide applicators in Sweden}

Two case-referent studies published in 1984 found an increased risk for testicular cancer among agricultural workers $(1,2)$, whereas a recent study failed to observe such a relationship (4).

We have studied the trends in cancer risks among agricultural workers in Sweden by following a cohort of agricultural workers between 1961 and 1979 (5). The cohort included 254417 men born between 1891 and 1940 and employed in agriculture according to the 1960 nationwide census. The reference cohort consisted of 1725845 men gainfully employed in other economic activities in 1960. The two cohorts were followed-up in the Swedish Cancer Register. The relative risk for testicular cancer increased over time from 0.83 in the time period $1961-1966$ to 0.94 in $1967-1973$ and to 1.35 in 1974-1979 (table 1). The increment was seen in all year-of-birth groups (5-year classes). There was also an increase in relative risk for cancer of the penis and/or the scrotum from 0.58 in the first period to 1.16 in the third and for cancer of prostate from 0.90 to 1.01 , respectively.

In Sweden the age-standardized incidence for testicular cancer per 100000 persons has increased from 2.5 in 1960 to 3.7 in 1982 (3). Estimates of the agestandardized incidence per 100000 in the agricultural and reference cohorts were calculated for each of the three time periods and are shown in figure 1 . These estimates are rough and should only be considered as an indication of tendency over time. The estimated agestandardized incidence increased during the study period in both cohorts. For the agricultural cohort, however, there was a steeper rise between period 2 and 3 than in the reference cohort, and in the third period the age-standardized incidence was highest in the agricultural cohort.

Clues to risk factors can be obtained from a study of the changes in cancer risks together with changes in the environment. Farming in Sweden has undergone radical changes since the 1940s. Prominent developments are increased mechanization and specialization and increased use of fertilizers and pesticides. Some of these changes may be responsible for the observed increase in relative risk and incidence among agricultural workers.

If exposure to pesticides or other agricultural chemicals is a risk factor for testicular cancer, an elevated risk should be found among licensed pesticide applicators. We have therefore also studied a cohort of 20245 men who had a license issued between 1965 and 1976. The cohort was followed-up in the Swedish Cancer Register until 31 December 1982. Approxi-

Table 1. Number of cases among agricultural and forestry workers and the estimated relative risks and $95 \%$ confidence intervals for the studied time periods.

\begin{tabular}{lccc}
\hline $\begin{array}{l}\text { Time } \\
\text { period }\end{array}$ & $\begin{array}{c}\text { Number } \\
\text { of cases }\end{array}$ & $\begin{array}{c}\text { Relative } \\
\text { risk }\end{array}$ & $\begin{array}{c}95 \% \\
\text { confidence } \\
\text { interval }\end{array}$ \\
\hline $1961-1966$ & 37 & 0.83 & $0.59-1.18$ \\
$1967-1973$ & 42 & 0.94 & $0.67-1.32$ \\
$1974-1979$ & 38 & 1.35 & $0.94-1.93$ \\
\hline
\end{tabular}

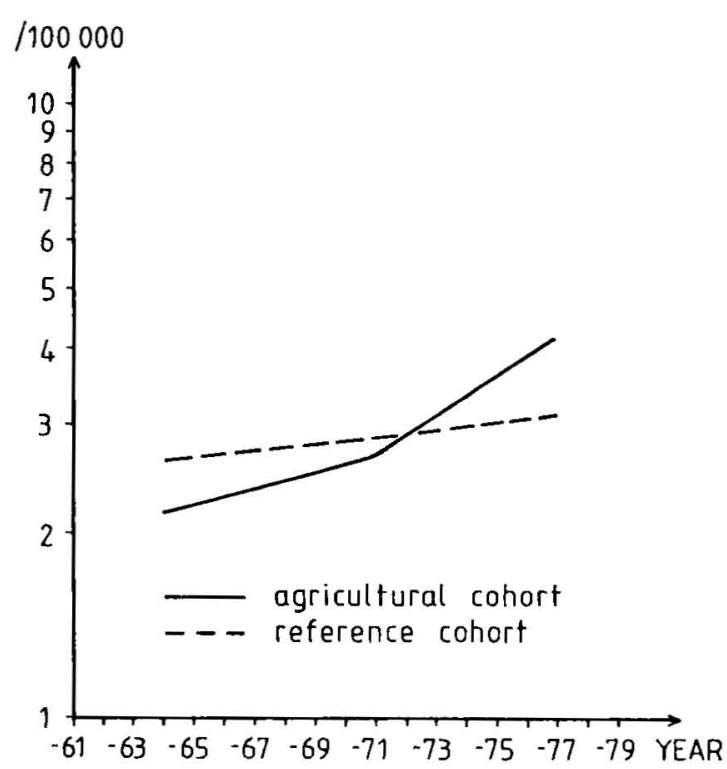

Figure 1. Estimated age-standardized incidence of testicular cancer per 100000 persons.

mately half of the men in this cohort were born in 1935 or later. A total of 18 cases of testicular cancer was observed against 11.6 expected. The estimated relative risk was calculated as 1.55 (95\% confidence interval $0.92-2.45$ ).

In summary, these Swedish studies indicate an elevated risk, though not statistically significant, for testicular cancer among agricultural workers at the end of the 1970s and among licensed pesticide applicators. For agricultural workers there was also an increase over time from under towards above unity for the estimated relative risk. 


\section{References}

1. McDowall M, Balarajan R. Testicular cancer and employment in agriculture. Lancet 1 (1984) 510-511.

2. Mills PK, Newell GR, Johnson DE. Testicular cancer associated with employment in agriculture and oil and natural gas extraction. Lancet 1 (1984) 207-210.

3. National Board of Health and Welfare. The Cancer Registry: Cancer incidence in Sweden 1982. Stockholm 1985.

4. Sewell CM, Castle SP, Hull HF. Testicular cancer and employment in agriculture and oil and natural gas extraction. Lancet 1 (1986) 553.
5. Wiklund $\mathrm{K}$, Holm L-E. Trends in cancer risks among Swedish agricultural workers. J Natl Cancer Inst 77 (1986) 657-664.

Kerstin Wiklund, DrMedSc, Jan Dich, MSc, Lars-Erik Holm, MD ${ }^{1}$

${ }^{1}$ Department of Cancer Epidemiology

Radiumhemmet

Karolinska University Hospital

S-104 01 Stockholm, Sweden 